\title{
Vitamin A deficiency and associated factors in preschoolers from the outskirts of La Plata, Buenos Aires
}

\author{
Liliana Disalvo, Biochemist ${ }^{a}$, Ana Varea, Biochemist ${ }^{a}$, Natalia Matamoros, Biochemist ${ }^{a}$, \\ Agustina Malpeli, B.S. ${ }^{a}$, María V. Fasano, M.D. ${ }^{a}$ and Horacio F. González, M.D. ${ }^{a}$
}

\begin{abstract}
Introduction. Vitamin A deficiency (VAD) has been recognized as an important public health problem in developing countries. Preschoolers account for risk groups within vulnerable populations. The objective of this study was to determine the prevalence of VAD and associated factors in a sample of preschoolers.

Material and methods. Cross-sectional study with children aged 1-6 years receiving social assistance and seen at primary health care centers in the outskirts of the city of La Plata, Buenos Aires. Vitamin A levels were determined by measuring serum retinol with a liquid chromatography; anthropometric parameters and dietary intake were recorded. A multinomial logistic regression model was used to assess the association among outcome measures.

Results. Data from 624 children were analyzed. The geometric mean of retinol was $23.8 \mu \mathrm{g} / \mathrm{dL}$ (95 \% CI: 23.3-24.3). The prevalence of VAD and the risk for VAD were $24.3 \%$ and $57.4 \%$, respectively. Retinol levels were significantly lower among boys, low-weight children, and those with low intake (below the first tertile of distribution). The multivariate analysis showed a significant association between VAD and male sex (odds ratio: 1.93; $95 \%$ CI: 1.15-3.24) and between VAD and low intake (odds ratio: 1.48; $95 \%$ CI: 1.15-2.62).

Conclusion. The prevalence of $\operatorname{VAD}(24.3 \%)$ is a major public health problem in this population. VAD-associated factors were male sex and low vitamin A intake.

Key words: retinol, vitamin Adeficiency, preschooler,
\end{abstract} risk factors.

http: / / dx.doi.org/10.5546/ aap.2019.eng.19

To cite: Disalvo L, Varea A, Matamoros N, Fasano $\mathrm{MV}$, et al. Vitamin A deficiency and associated factors in preschoolers from the outskirts of La Plata, Buenos Aires. Arch Argent Pediatr 2019;117(1):19-25.

\section{INTRODUCTION}

Vitamin A (retinol) is an essential nutrient that, in small amounts, is necessary for a normal functioning of the visual system, adequate growth and development, epithelial cell integrity, red blood cell production, immunity, and reproduction. ${ }^{1}$

The groups that are most vulnerable to vitamin A deficiency (VAD) include infants, preschoolers, and pregnant women. ${ }^{2} \mathrm{VAD}$ is the leading cause of preventable blindness in children and contributes greatly to increased morbidity and mortality from infections. ${ }^{3}$

VAD has been recognized as an important public health problem in developing countries. In 2009, the World Health Organization (WHO) estimated that $33 \%$ of the world population had VAD, with a prevalence of $15.4 \%$ in the Americas. ${ }^{1}$

The primary cause of VAD is an inadequate dietary intake, especially with low-quality or poorly diverse diets. However, it may also occur as a result of other factors, such as the presence of frequent infections, socioeconomic conditions, and accelerated growth and development, like what happens in certain stages in life. ${ }^{4}$ In this context, low-income populations receiving social assistance with limited access to healthy food and a low consumption of fruits and vegetables may be at a higher risk for VAD. ${ }^{5}$

In Argentina, there is little information about the nutritional status of vitamin A. The National Survey on Nutrition and Health (Encuesta Nacional de Nutrición y Salud, ENNyS), which covered all 
socioeconomic strata of Argentina, showed that the prevalence of VAD in children aged 2-5 years was $14.3 \%$, with variations among the different regions. ${ }^{6}$

The objective of this study was to determine the prevalence of VAD and the associated factors in a sample of preschoolers seen at primary health care centers in the outskirts of the city of La Plata, province of Buenos Aires, Argentina.

\section{MATERIAL AND METHODS}

This was a cross-sectional study that was part of a larger intervention called "Comprehensive intervention in management and harmonization of dietary programs aimed at improving the population's nutritional status." 7 This study describes the baseline results.

The sample was selected by convenience, in a non-probabilistic fashion. Participants were clinically healthy children aged 1-6 years whose families were receiving social assistance, seen at primary health care centers located in the outskirts of the city of La Plata, province of Buenos Aires, during 2010 and 2011. Children diagnosed with chronic, acute or infectious diseases at the time of the study and those whose parents or adult caregivers refused to participate were excluded.

Health care centers were selected based on the availability of a pediatrician interested in collaborating with the project. Pediatricians and health care promoters from each center invited all families who had regular health checkups there, and children who attended on the day of the assessment were included.

\section{Sample size calculation}

Considering that the sample was not estimated for the purpose of this study, the sample error was retrospectively calculated. In these circumstances, and based on the prevalence of VAD observed in this study $(24.3 \%)$, the sample size allowed to determine observed results with a $3.4 \%$ error, considering a $95 \%$ confidence interval (CI).

\section{Ethical considerations}

The study was carried out in accordance with the guidelines established by the Declaration of Helsinki, and a written informed consent was obtained from all participating children's parents or legal guardians. The protocol was approved by the Institutional Research Protocol Review Committee (Comité Institucional de Revisión de Protocolos de Investigación, CIRPI) of the
Pediatric Research and Development Institute of Hospital de Niños "Sor María Ludovica" of La Plata.

\section{Data collection instruments and techniques Biochemical indicators}

Fasting blood samples were collected by venipuncture in all children to measure vitamin A and serum retinol levels. Once collected, blood samples were protected from light and stored at $-70{ }^{\circ} \mathrm{C}$ until processing.

Serum retinol was measured using the procedure recommended by the Spanish Society of Clinical Biochemistry and Molecular Pathology (Sociedad Española de Bioquímica Clínica y Patología Molecular, SEQC). ${ }^{8}$ The samples were analyzed by ultrafast liquid chromatography (UFLC) in a Shimadzu Prominence equipment with diode array detector, wavelength of maximum absorption, Lamba max. $=325 \mathrm{~nm}$, and a Shim-Pack ODS II $3.0 \mathrm{~mm} \times 75 \mathrm{~mm}$ chromatographic column (particle size: $2.2 \mu \mathrm{m}$ ). The identification and measurement of retinol in blood samples were established by comparison with the retention times and areas of an all-transretinol standard (SIGMA).

Serum retinol levels were classified into three categories: $\operatorname{VAD}(<20 \mu \mathrm{g} / \mathrm{dL})$, at risk for VAD $(\geq 20 \mu \mathrm{g} / \mathrm{dL}$ and $<30 \mu \mathrm{g} / \mathrm{dL})$, and adequate $(\geq 30 \mu \mathrm{g} / \mathrm{dL})^{9}$

\section{Anthropometric indicators}

Weight and height were measured using standard techniques by nutritionists who were trained in advance. ${ }^{10}$ Weight was measured using a digital electronic scale (Tanita UM-061, precision $0.1 \mathrm{~g}$, Tanita Corporation of America Inc., Illinois, USA). Height was measured using a portable stadiometer (precision $0.5 \mathrm{~cm}$, SECA, United Kingdom). Weight-for-age (WA), heightfor-age (HA), and body mass index (BMI) indicators were developed and assessed using the tables proposed by the WHO. ${ }^{11}$ The following indicators were used for nutritional classification:

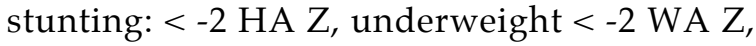
overweight $>+1$ BMI Z-score, and obesity $>+2.0$ BMI Z-score.

\section{Dietary intake}

Vitamin A dietary intake ( $\mu \mathrm{g}$ of retinol equivalent [RE]) was assessed by means of a 24-hour recall interview with the adult caregiver of each child conducted by trained nutritionists using the multi-step technique. ${ }^{12}$ 
The recall interview was done so that all week days were represented, except when the child's intake on the previous day had been affected by a disease. Quantities and servings were standardized using food replica kits and visual aids. ${ }^{13}$ Reported food, beverage, and supplement quantities were translated into nutrients using the chemical composition tables by the United States Department of Agriculture (USDA). ${ }^{14}$ Vitamin A intake was stratified according to distribution tertiles; the first tertile was considered low intake and the rest, a reference intake.

\section{Statistical analysis}

The R statistical package, version 3.3.2, was used for statistical analysis. The KolmogorovSmirnov test was used to analyze outcome measure normality. Vitamin A levels were described as geometric mean (GM) and $95 \% \mathrm{CI}$, due to their lognormal distribution. Vitamin A intake was reported as median and interquartile range (IQR); the other outcome measures were described as mean \pm standard deviation due to their normal distribution. Qualitative outcome measures were expressed as frequency (\%). Student's test was used to compare the mean between two groups and the analysis of variance (ANOVA), for more than two groups.

A multinomial logistic regression was done to determine VAD-associated factors. The strength of the association was described using odds ratio (OR) $(95 \% \mathrm{CI})$.

The first stage of the analysis was done using a bivariate multinomial logistic regression to study the association of each outcome measure with VAD. VAD-associated outcome measures with a $p$ value $<0.20$ in the bivariate analysis were then selected and included in a multivariate analysis. The backward stepwise method was used with the Akaike information criterion (AIC) to select outcome measures in the final explanatory model.

\section{RESULTS}

The data of 624 children aged 1-6 years participating in the original study were analyzed. The characteristics of the population are presented in Table 1.

The GM of vitamin A was $23.8 \mu \mathrm{g} / \mathrm{dL}$ (95\% CI: 23.3-24.3). The prevalence of VAD and the risk for VAD were $24.4 \%$ and $57,4 \%$, respectively. Only 2 children $(0.3 \%)$ had severe VAD (vitamin A: $<10 \mu \mathrm{g} / \mathrm{dL}$ ).

The median vitamin A intake was $236.7 \mu \mathrm{g} /$ day (105.6-436.9); with the stratification of intake into tertiles, values below $148.8 \mu \mathrm{g} /$ day (first tertile) were considered low intake of vitamin A.

Table 2 shows the comparison of the mean serum retinol levels by studied outcome measures. Statistically significant differences were observed by sex and nutritional status of children based on the WA and BMI indicators.

\section{Factors associated with vitamin A deficiency}

The bivariate analysis showed a statistically significant association between VAD and male sex (OR: 1.81; 95 \% CI: 1.11-2.95) (Table 3). The prevalence of VAD was $29.5 \%$ in boys and $19.6 \%$ in girls $(p=0.015)$. No statistically significant differences were observed in relation to the other outcome measures. Since there were no lowweight children with adequate retinol levels, it was not possible to estimate the OR as per the WA Z-score indicator.

The multivariate analysis included the following outcome measures: sex, age category, overweight/obesity, and vitamin A intake. After the selection of outcome measures, the final model included sex and vitamin A intake below the first tertile. This analysis confirmed the association between VAD and male sex (OR: 1.93; $95 \%$ CI: 1.15-3.24) and between VAD and vitamin A intake below the first tertile (OR: 1.48; $95 \%$ CI: 1.15-2.62) (Table 4).

TABLE 1. Characteristics of studied children $(n=624)$

\begin{tabular}{lc}
\hline Outcome measures & $\begin{array}{c}\mathbf{n}(\%) \\
\text { Mean } \pm \text { SD }\end{array}$ \\
\hline Age (years old) & $3.41 \pm 1.51$ \\
Age distribution in years old & \\
$1-1.9$ & $158(25.3)$ \\
$2-2.9$ & $114(18.3)$ \\
$3-3.9$ & $117(18.7)$ \\
$4-4.9$ & $121(19.4)$ \\
$5-5.9$ & $114(18.3)$ \\
Sex & \\
Male & $302(48.4)$ \\
Female & $322(51.6)$ \\
Anthropometric measures & \\
WAZ & $0.01 \pm 1.14$ \\
Low weight $(\mathrm{n}=618)$ & $17(2.8)$ \\
HAZ & $-0.67 \pm 1.13$ \\
Chronic growth retardation $(\mathrm{n}=615)$ & $68(11.1)$ \\
BMIZ & $0.61 \pm 1.18$ \\
Overweight/obesity & $209(33.9)$ \\
\hline
\end{tabular}

SD: standard deviation; WAZ: weight-for-age Z-score; HAZ: height-for-age Z-score; BMIZ: body-mass-index Z-score. 


\section{DISCUSSION}

Our findings show that $24.4 \%$ of children have VAD and that more than $50 \%$ are at risk for developing it. These values exceed the prevalence reference limits established by the $\mathrm{WHO}^{15}(>20 \%)$, making VAD a serious public health problem.

In Latin America, VAD prevalence in children younger than 5 years ranges from below $2 \%$ in Guatemala and Nicaragua to $32 \%$ in Haiti. ${ }^{16}$ Our findings are similar to those of other studies conducted in Colombia and Brazil, ${ }^{17-18}$ which reported that $24.3 \%$ and $24.7 \%$ of children aged between 1 and 5 years had VAD, and higher than those reported by other authors in the region. ${ }^{19-21}$ Such differences in prevalence are probably a reflection of each country's or region's specific characteristics.

Comparing our findings to the data available in our country, our prevalence was higher than that reported by the ENNyS, which included a population sample of all socioeconomic strata and reported a $14.3 \%$ VAD prevalence in children
2-5 years old. ${ }^{5}$ Most likely, such difference is because our results correspond to a sample focused on a vulnerable population. In addition, a study conducted by our research group, which assessed the impact of a dietary program on a population of children with similar characteristics (low-income families receiving food aid), found a similar prevalence. ${ }^{22}$ In spite of the 10 years elapsed between both studies, VAD prevalence is still high. In contrast, Guatemala has managed to become the Latin American country with the lowest VAD prevalence through staple food fortification with vitamin A more than 20 years ago. ${ }^{23}$

Among analyzed factors, in this study, VAD was associated with male sex and a low vitamin A intake. Boys had a higher risk for VAD than girls, which is consistent with the findings of Tariku et al. ${ }^{24}$ and different from what was observed by other authors who reported a similar deficiency prevalence in both sexes. ${ }^{25-27}$

In addition, as seen with other nutritional deficiencies, a diet that is chronically insufficient

TABLE 2. Comparison of mean vitamin A (serum retinol) levels as per studied outcome measures

\begin{tabular}{|c|c|c|c|}
\hline Outcome measure & $\mathbf{n}$ & $\begin{array}{c}\text { GM }(95 \% \text { CI }) \\
(\mu \mathrm{g} / \mathrm{dL})\end{array}$ & $p$ value ${ }^{*}$ \\
\hline \multicolumn{4}{|l|}{ Sex } \\
\hline $\mathrm{F}$ & 322 & $24.43(23.72-25.15)$ & \multirow{2}{*}{0.007} \\
\hline M & 302 & $23.19(22.48-23.92)$ & \\
\hline \multicolumn{4}{|l|}{ Age (years old) } \\
\hline $1-1.9$ & 158 & $23.49(22.56-24.46)$ & \multirow{5}{*}{$0.653+$} \\
\hline $1-2.9$ & 114 & $24.53(23.15-25.98)$ & \\
\hline 3-3.9 & 117 & $23.76(22.62-24.96)$ & \\
\hline $4-4.9$ & 121 & $23.40(22.26-24.60)$ & \\
\hline $5-5.9$ & 114 & $24.09(23.01-25.23)$ & \\
\hline \multicolumn{4}{|l|}{ WAZ } \\
\hline LW & 17 & $18.93(16.06-22.30)$ & \multirow{2}{*}{0.008} \\
\hline Normal & 601 & $23.92(23.42-24.44)$ & \\
\hline \multicolumn{4}{|l|}{ HAZ } \\
\hline CGR & 68 & $23.80(22.24-25.46)$ & \multirow[b]{2}{*}{0.978} \\
\hline Normal & 547 & $23.77(23.24-24.32)$ & \\
\hline \multicolumn{4}{|l|}{ BMIZ } \\
\hline $\mathrm{O} / \mathrm{O}$ & 209 & $24.32(23.44-25.23)$ & \multirow[b]{2}{*}{0.041} \\
\hline Normal & 404 & $23.46(22.85-24.09)$ & \\
\hline \multicolumn{4}{|l|}{ Vitamin A intake $\neq$} \\
\hline$<\mathrm{T}_{1}$ & 189 & $23.32(22.43-24.24)$ & \multirow{2}{*}{0.298} \\
\hline$\geq \mathrm{T}_{1}$ & 378 & $23.92(23.36-24.59)$ & \\
\hline
\end{tabular}

* Student's test.

+ ANOVA test.

‡ Only 567 24-hour recall interviews were done. T1: first intake tertile $=148.8 \mu \mathrm{g} /$ day.

LW: low weight; CGR: chronic growth retardation; O/O: overweight/obesity; WAZ: weight-for-age Z-score;

HAZ: height-for-age Z-score; BMIZ: body-mass-index Z-score; GM: geometric mean. 
in vitamin A can lead to lower liver stores and fail to meet physiologic needs. ${ }^{1}$ Peng et al., in a study conducted in children aged 2-7 years, found a significant relationship between vitamin A dietary intake and retinol levels. ${ }^{28}$ In this study, although no differences were observed in serum retinol levels by vitamin A intake category, children with a low vitamin A intake, defined as an intake below the first tertile, had a greater risk for VAD than the rest.

In relation to children's age, in our study we did not observe differences in retinol levels when comparing age groups, similar to what has been observed in preschoolers by other authors. ${ }^{17,27}$
The results of the anthropometric assessment of nutritional status showed that, on the one side, low-weight children had significantly lower serum retinol levels than children with a normal weight; moreover, none of the children with a low weight had adequate vitamin A levels. Similarly, in a study carried out in schoolchildren, Ribeiro-Silva et al. found that those with a low weight had twice the risk for VAD than normal weight children. ${ }^{29}$ Such analysis was not possible in our study because none of the children with a low weight had adequate vitamin A levels (comparison group). In addition, unlike what has been reported by other authors, ${ }^{30-31}$ retinol levels

TABLE 3. Association between vitamin A deficiency and studied outcome measures. Bivariate model

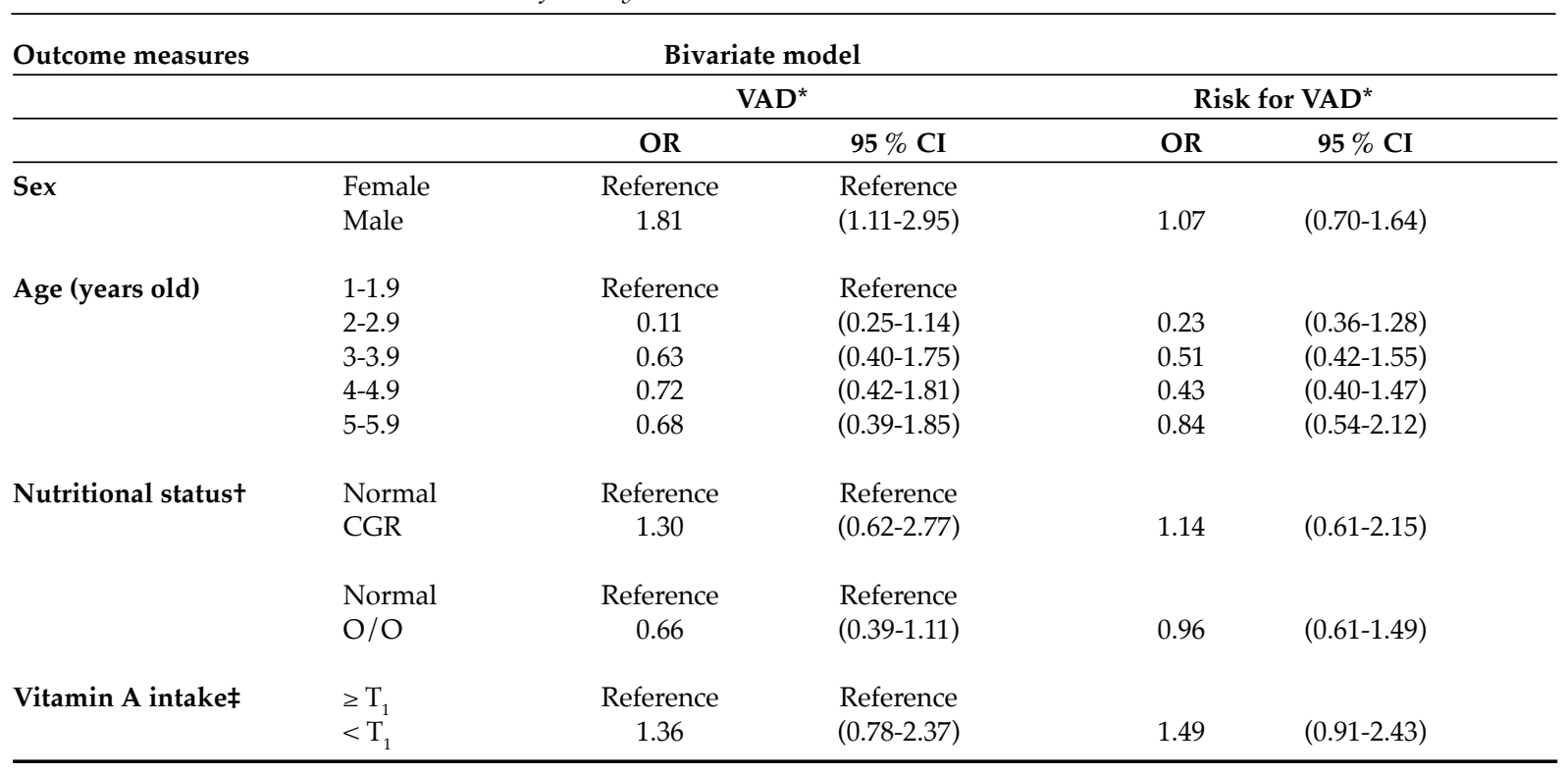

OR: odds ratio; VAD: vitamin A deficiency; CI: confidence interval; O/O: overweight/obesity.

* Adequate vitamin A levels: retinol $\geq 30 \mu \mathrm{g} / \mathrm{dL}$ (comparison group).

† The low/normal weight categories are not included because no child with low weight had adequate retinol levels.

₹ T1: $148.8 \mu \mathrm{g} /$ day.

Vitamin A intake $\geq \mathrm{T} 1$ (comparison group).

TABLE 4. Association between vitamin A deficiency and studied outcome measures. Multivariate model

\begin{tabular}{|c|c|c|c|c|c|}
\hline \multirow[t]{3}{*}{ Outcome measures } & & \multicolumn{4}{|c|}{ Multivariate model } \\
\hline & & \multicolumn{2}{|c|}{ VAD $^{*}$} & \multicolumn{2}{|c|}{ Risk for VAD* } \\
\hline & & OR & $95 \% \mathrm{CI}$ & OR & $95 \% \mathrm{CI}$ \\
\hline Sex & $\begin{array}{l}\text { Female } \\
\text { Male }\end{array}$ & $\begin{array}{c}\text { Reference } \\
1.93\end{array}$ & $\begin{array}{l}\text { Reference } \\
(1.15-3.24)\end{array}$ & 1.04 & $(0.66-1.64)$ \\
\hline Vitamin A intake $\ddagger$ & $\begin{array}{l}\geq \mathrm{T}_{1} \\
<\mathrm{T}_{1}\end{array}$ & $\begin{array}{c}\text { Reference } \\
1.48\end{array}$ & $\begin{array}{l}\text { Reference } \\
(1.15-2.62)\end{array}$ & 1.61 & $(0.97-2.66)$ \\
\hline
\end{tabular}

OR: odds ratio; VAD: vitamin A deficiency; IC: confidence interval.

Adjustment outcome measures: sex, age, overweight/obesity, and vitamin A intake.

* Adequate vitamin A levels: retinol $\geq 30 \mu \mathrm{g} / \mathrm{dL}$ (comparison group).

₹ T1: $148.8 \mu \mathrm{g} /$ day.

Vitamin A intake $\geq \mathrm{T} 1$ (comparison group). 
in children with overweight/obesity were mildly higher than in normal weight children, although no association with VAD was observed.

Our findings evidence the magnitude of VAD in preschoolers, a problem that has been scarcely studied in our region. However, this study has limitations. First of all, our findings are only representative of the children seen in the public health system, whose families receive social assistance, and may not be extrapolated to the general population from the outskirts of the city of La Plata. Secondly, the 24-hour recall interview method to study food consumption also has certain limitations, although it is adequate to estimate the average population intake, even if used only once. ${ }^{32}$ Finally, since this is a crosssectional study, it only provides scarce evidence of causality.

Based on the findings, and considering that VAD in children is associated with respiratory and diarrheal diseases and with an increase in their frequency, severity, and mortality, ${ }^{33}$ it is necessary to strengthen health interventions to allow the systematic implementation of prevention measures, mostly focused on nutritional education. Although our findings may not be generalized to the entire population, they provide an important piece of evidence for planning public policies.

In order to reduce $\mathrm{VAD}$, besides prevention strategies such as food fortification or supplementation, it is necessary to consider the risk factors for it.

\section{CONCLUSION}

The prevalence of VAD $(24.3 \%)$ is a major public health problem in this population. VADassociated factors were male sex and a low vitamin A intake.

\section{Acknowledgments}

The authors would like to thank the health team of each center who helped with children assessment, parents and caregivers, and children for participating in this study.

\section{REFERENCES}

1. World Health Organization. Global prevalence of vitamin A deficiency in populations at risk 1995-2005. WHOglobal database on vitamin A deficiency. Geneva: WHO; 2009. [Accessed on: August 6, 2018]. Available at: whqlibdoc. who.int/publications / 2009/9789241598019_eng.pdf.

2. WestKPJr. Extent of vitamin A deficiency among preschool children and women of reproductive age. J Nutr 2002; 132(Suppl 9):S2857-66.

3. McLaren DS, Kraemer K. Xerophthalmia. World Rev Nutr
Diet 2012; 103:65-75.

4. Hanson C, Lyden E, Abresch C, Anderson-Berry A. Serum retinol concentrations, race, and socioeconomic status in women of childbearing age in the United States. Nutrients 2016; 8(8):e508.

5. AbeyáGilardonEO. Una evaluación crítica delos programas alimentarios en Argentina. Salud Colect 2016; 12(4):589-604.

6. Durán $P$, Mangialavori G, Biglieri A, et al. Estudio descriptivo de la situación nutricional en niños de 6-72 meses de la República Argentina. Resultados de la Encuesta Nacional de Nutrición y Salud. Arch Argent Pediatr 2009; 107(5):397-404

7. GonzálezHF, Orden B, Disalvo L, etal. Intervención integral en gestión y armonización de programas alimentarios para mejorar el estado nutricional de la población. [Accessed on: August 6, 2018]. Available at: https://es.scribd.com/ doc/52592745/Programas-Alimentarios.

8. Comisión de Vitaminas de la Sociedad Española de Química Clínica (SEQC). Procedimiento recomendado para la determinación de retinol en suero o plasma. Quím Clín 1998; 17(1):38-42.

9. Sommer A, Davidson FR, Annecy A. Assessment and control of vitamin A deficiency: The Annecy Accords. J Nutr 2002; 132(Suppl 9):S2845-50.

10. Comité Nacional deCrecimientoy Desarrollo. Guías para la Evaluación delCrecimiento. 2.a ed. Buenos Aires: Sociedad Argentina de Pediatría; 2001.

11. De Onis M, Onyango AW, Borghi E, et al. Comparison of the World Health Organization (WHO) Child Growth Standards and the National Center for Health Statistics/ WHOInternational Growth Reference:Implications for child health programmes. Public Health Nutr 2006; 9(7):942-7.

12. Gibson RS. Principles of nutritional assessment. $2^{\text {nd }}$ ed. New York: Oxford University Press; 2005.

13. Vázquez MB, Witriw AM. Modelos visuales de alimentos y tablas de relación peso/volumen. Buenos Aires: Edición del autor; 1997.

14. USDA. Food Search for Windows, Version 1.0, Database version SR17. [Accessed on: August 6, 2018]. Available at: http: / / www.access-pro.de/blog-USDA-NationalNutrient-Database-Food-Search-for-Windows.php.

15. World Health Organization. Indicators for assessing vitamin A deficiency and their application in monitoring and evaluation intervention programmes. Geneva: WHO; 1996. [Accessed on: August 6, 2018]. Available at: whqlibdoc. who.int/hq/1996/WHO_NUT_96.10.pdf.

16. Cediel G, Olivares M, Brito A, et al. Interpretation of serum retinol data from Latin America and the Caribbean. Food Nutr Bull. 2015; 36(2 Suppl):S98-108.

17. Martínez-Torres J, Meneses-Echáves JF, Ramírez-Vélez R. Prevalencia de deficiencia subclínica de vitamina A y factores sociodemográficos asociados en niños de 1259 meses de edad en Colombia. Endocrinol Nutr 2014; 261(9):460-6.

18. Saraiva BC, Soares MC, Santos LC, et al. Iron deficiency and anemia are associated with low retinol levels in children aged 1 to 5 years. J Pediatr (Rio J) 2014; 90(6):593-9.

19. Kurihayashi AY, Augusto RA, Escaldelai FM, Martini LA. Estado nutricional de vitaminas A e D em crianças participantes de programa de suplementação alimentar. Cad Saúde Pública 2015; 31(3):531-42.

20. Novaes TG, Gomes AT, SilveiraK KC, et al. Prevalence and factors associated to vitamin A deficiency in children attending public day care centers in the Southwest of Bahia. Rev Bras Saude Mater Infant 2016; 16(3):337-44.

21. VillalpandoS, Cruz V deL, Shamah-Levy T, etal. Nutritional status of iron, vitamin B12, folate, retinol and anemia in children 1 to 11 years old: Results of the Ensanut 2012. 
Salud Pública Mex 2015; 57(5):372-84.

22. Varea A, Malpeli A, Etchegoyen G, et al. Short-term evaluation of the impact of a food program on the micronutrient nutritional status of Argentinean children under the age of six. Biol Trace Elem Res 2011; 143(3):1337-48.

23. Krause VM, Delisle H, Solomons NW. Fortified foods contribute one half of recommended vitamin A intake in poor urban Guatemalan toddlers. J Nutr 1998; 128(5):860-4.

24. Tariku A, Fekadu A, Ferede AT, et al. Vitamin-A deficiency and its determinants among preschool children: a community based cross-sectional study in Ethiopia. BMC Res Notes 2016; 9:323.

25. Ferraz IS, Daneluzzi JC, Vannucchi H. Vitamin A deficiency in children aged 6 to 24 months in São Paulo State, Brazil. Nutr Res 2000; 20(6):757-68.

26. Nestel P, Melara A, Rosado J, Mora J. Vitamin A deficiency and anemia among children12-71 months old in Honduras. Rev Panam Salud Pública 1999; 6(1):34-43.

27. Martins MC, Santos L, Assis A. Prevalência da hipovitaminose A em pré-escolares no Estado de Sergipe, 1998. Rev Saúde Pública 2004; 38(4):537-42.
28. Peng $P$, Wei $X$, Liang $X$, et al. Effect of dietary vitamin A intake on plasma vitamin Aconcentration in preschool children of Banan district, Chongqing, China. Beijing $D a$ Хue Xue Bao Yi Xue Ban 2014; 46(3):366-72.

29. Ribeiro-Silva RC, Nunes IL, Assis AM. Prevalence and factors associated with vitamin A deficiency in children and adolescents. J Pediatr (Rio J). 2014; 90(5):486-92.

30. Sarni RO, Souza FI, Ramalho RA, et al. Serum retinol and total carotene concentrations in obese pre-school children. Med Sci Monit 2005; 11(11):CR510-4.

31. Wei X, Peng R, Cao J, et al. Serum vitamin A status is associated with obesity and the metabolic syndrome among school-age children in Chongqing, China. Asia Pac J Clin Nutr 2016; 25(3):563-70.

32. Willett W. Nutritional Epidemiology. New York: Oxford University Press, 1990.

33. Stevens GA, BennettJE,HennocqQ, etal. Trendsandmortality effects of vitamin A deficiency in children in 138 low-income and middle-income countries between 1991 and 2013: a pooled analysis of population-based surveys. Lancet Glob Health 2015; 3(9):e528-36. 